\title{
Microeconomia reducionista e microeconomia sistêmica
}

Eleutério F. S. Prado Professor da USP

\section{Palauras-chave}

microeconomia evolucionária, microeconomia sistêmica, racionalidade adaptativa, racionalidade limitada, problema da composição.

\section{Classificação JEL B41, B52,} D01.

\author{
Key words \\ evolutionary microeconomics, \\ systemic microeconomics, \\ adaptive rationality, \\ procedural rationality, \\ composition problem.
}

JEL Classification B41, B52, D01.

\section{Resumo}

No artigo sustenta-se que outra microeconomia, metodologicamente diferente do reducionismo neoclássico, está em processo de rápido desenvolvimento: a microeconomia sistêmica e evolucionária. A anterior baseiase em agentes clarividentes, que se informam, mas não se instruem, e que agem com racionalidade substantiva. A última funda-se em agentes parcialmente cegos, que aprendem e que atuam racionalmente de modo adaptativo. Mostra-se que o fulcro da diferença entre essas duas alternativas encontra-se no modo de conectar as partes entre si e as partes com o todo. Na primeira, os agentes são independentes entre si e as propriedades globais são obtidas por agregação. $\mathrm{Na}$ segunda, os agentes encontram-se organizados pelas estruturas sociais e formam composições que têm propriedades emergentes. Assim, as partes e o todo se pertencem, ou seja, são inseparáveis. $\mathrm{Na}$ primeira, os agentes são definidos apenas por suas propriedades intrínsecas, mas na segunda o são também por suas propriedades relacionais.

\section{Abstract}

This paper argues that another microeconomics, methodologically different from neoclassical reductionism, is rapidly developing: systemic and evolutionary microeconomics. The former is based on clear-sighted agents that have access to information but do not really learn, and always proceed with substantive rationality. The latter is based on partially blind agents who learn and act rationally in an adaptive way. The study demonstrates that the crux of the difference between these two alternatives is the way they connect the parts among themselves and the parts to the whole. In the former, the agents are independent of each other and global properties are obtained by aggregation. In the latter, the agents are organized by social structures and they form compositions that have emergent properties. Therefore, the parts and the whole belong to each other; that is, they are inseparable. In the former, the agents are defined only by their intrinsic properties, but in the latter, they are also defined by their relations. 


\section{1_Introdução}

Acredita-se usualmente entre os economistas que a microeconomia neoclássica é uma disciplina bem estabelecida e que se encontra consagrada em seus grandes traços. E essa imagem é transmitida nos livros didáticos que se costuma empregar nos cursos de graduação e de pós-graduação para ministrar a matéria que leva esse nome. Junto com essa constatação, a qual apenas registra o estado das coisas no ensino e na difusão dos conhecimentos econômicos, têm-se como certas várias idéias bem duvidosas.

Pensa-se generalizadamente que a abordagem largamente dominante, e que pode ser classificada como neowalrasiana, é a única que produz uma inteligibilidade abrangente dos fenômenos econômicos. Julga-se normalmente que esse modo de teorizar, o qual se preocupa centralmente com a coerência possível do sistema econômico, é, em exclusivo, aquele capaz de apresentar tais fenômenos como decorrentes das decisões de agentes racionais (em sentido instrumental, obviamente). Ademais, acredita-se firmemente que esse modo fundado em decisões maximizadoras respeita a idéia clássica de "mão invisível". Sob tal visão, chega-se a pensar que os mercados aproveitam otimamente as decisões autocen- tradas e independentes de um sem número de unidades econômicas para produzir um resultado global que se afigura como consistente e benéfico para todos os seus participantes.

Neste artigo contesta-se essa visão, mostrando metodologicamente que outra microeconomia é possível e que ela já está em desenvolvimento. O argumento aqui desenvolvido sustenta-se numa visão alternativa. Acredita-se que a microeconomia sistêmica e evolucionária convém melhor ao entendimento dos mercados realmente existentes, uma vez que permite compreendê-los em seu processo. Ademais, ela possibilita apresentar algumas características globais do sistema econômico por meio de uma noção de mão invisível mais fiel ao modelo encontrado em $A$ riqueza das naçoes. ${ }^{1}$ Em decorrência, pensa-se que a própria possibilidade da concepção triunfante, largamente hegemônica no século XX e atualmente, decorreu da repressão de um modo alternativo de pensar a esfera econômica. Esse outro modo encontra-se hoje em eclipse, mas foi originariamente empregado com enorme agudez e pertinência - ainda que de maneira pouco formalizada - pela economia política clássica. Para dar substância a essa visão, quer-se mostrar que a alternativa da microeconomia sistêmica e
,

Esse ponto foi

desenvolvido em outros

dois artigos em que se procurou discutir o conceito de mão invisível (Prado, 1993, 2006). Neste último, formaliza-se a mão invisível com base na noção de dinâmica de replicação. 
2 Um texto moderno que deu importantes contribuições para essa microeconomia foi o de Schelling. Em seu livro Micromotives and macrobehavior, ele considerou que "esse tipo de análise explora a relação entre os comportamentos característicos dos indivíduos que formam um agregado social e as características próprias desse agregado" (Schelling, 1978, p. 13). Aqui o que ele chama de "agregado social" é entendido não como mero agregado ou "soma", mas como composição social.

3 Ainda que a elaboração do vínculo seja matéria que exige extenso desenvolvimento, pode-se afirmar que a limitação da racionalidade tem relação com a incerteza keynesiana (Bateman, 1989; O’Donnell, 1989). Um estudo importante quanto às implicações do conceito de racionalidade procedimental para a teoria econômica, assim como uma crítica de suas limitações, foi feito por Vercelli (2005). evolucionária - que ganha hoje uma pertinente expressão matemática - vem a ser em princípio abrangente no trato dos fenômenos econômicos e é capaz de fundar as propriedades macroeconômicas na atuação microeconômica dos agentes, dotando-os também de racionalidade instrumental, mas não exclusivamente.

A defesa dessa tese será aqui apresentada por meio da contraposição entre dois modos de tratar as unidades econômicas, as suas interações e os resultados conjuntos das ações individuais. Um desses modos será denominado de microeconomia reducionista, e o outro, de microeconômica sistêmica. ${ }^{2}$ De maneira preliminar, pode-se dizer que, no primeiro caso, os agentes são entendidos como unidades de decisão clarividentes, dotadas de racionalidade grosso modo perfeita e já constituídas como tais em face das escolhas; no segundo, elas são vistas como parcialmente cegas, em processo de constituição para tomada de decisão e dotadas de racionalidade limitada. ${ }^{3}$

A mesma contraposição, a seu modo, foi feita por Simon. Ele distinguiu a racionalidade que atua nas situações em que o conhecimento é pleno, as expectativas são corretas e o resultado da ação é certo, chamando-a de substantiva. "O comportamento é substantivamente ra- cional" - diz ele - "quando é adequado para a obtenção de dados objetivos nas condições e limites existentes" (Simon, 1976). Pois, nas situações complexas, radicalmente incertas e pouco transparentes, prevalece uma racionalidade adaptativa que busca apenas o razoável. Eis que a "racionalidade procedimental" - em suas palavras - "resulta de deliberação apropriada e depende do processo que a gera" (Simon, 1976).

De maneira mais centrada, como os adjetivos empregados para caracterizá-los já indicam, a contraposição entre microeconomia reducionista e microeconomia sistêmica tem por fulcro o modo de conexão das partes entre si e das partes com o todo. No primeiro caso, os todos econômicos serão entendidos sempre como resultados gerados por meio de interações que se somam, ou seja, como agregações; no segundo, por outro lado, eles serão compreendidos como sistemas ou como composições globais, já que as interações que os constituem, constituem em processo também os próprios agentes enquanto tais.

Nessa segunda microeconomia, os componentes do sistema vão aparecer não como indivíduos autodeterminados, mas como agentes limitados, ou seja, como seres atuantes, mas que estão larga- 
mente determinados pela posição social que ocupam na estrutura existente de relações. Ao se considerar eventualmente a inversão entre sujeito e objeto que, segundo Marx, caracteriza o capitalismo, eles aparecem mesmo como suportes de relações sociais. ${ }^{4}$ Em perspectiva crítica, aliás, neste último caso, em vez de empregar termos abstratos como agente ou indivíduo para designar as unidades do sistema, vem a ser mais correto usar as determinações posicionais que os identificam, tais como trabalhador e capitalista.

Antes de prosseguir, é necessário mencionar que não se pretende tratar neste artigo da distinção entre a economia clássica e a economia neoclássica conquanto tais. Diferentemente, procura-se estabelecer nos planos da ontologia e da metodologia uma distinção entre dois modos alternativos de apreender a realidade econômica, os quais - crê-se - se firmaram histórica e concretamente, em grandes traços, nessas duas correntes teóricas.

A suposição central é que a ciência econômica, em sentido amplo, sempre procurou se assenhorear da realidade estabelecendo conexões sistemáticas entre as partes constituintes e as totalidades sociais constituídas. Mais precisamente, desde a sua origem, ela buscou encontrar os vínculos entre as propriedades dos elementos individuais - e/ou das relações sociais que estruturam e organizam esses elementos - e as propriedades globais resultantes de suas interações. Ao fazê-lo, tomou essas propriedades como decorrentes de mera agregação ou, alternativamente, como resultados que advêm da composição das partes e de seu processo de constituição. Ante a alta complexidade dessas totalidades, percorreu assim dois caminhos: um deles que se caracteriza por respeitar essa complexidade enquanto tal, e outro que está marcado pelo propósito de simplificá-la ao máximo.

\section{2_Diferenças lógicas gerais}

Ainda que a ciência econômica institucionalizada prefira se ver primeiramente por sua dimensão metodológica - ela é antes de tudo um procedimento sistemático para acumular conhecimento de relações aparentes sobre a esfera da produção, da repartição e do consumo -, vê-la por meio de sua dimensão ontológica permite ir mais a fundo no exame de sua natureza. ${ }^{5}$

A microeconomia reducionista orienta-se pelo propósito de apreender a complexidade do social por meio de um esquema explicativo que se conforma à exposição dedutiva. Em conseqüência,
4 Esta última perspectiva, como se sabe, encontra-se amplamente desenvolvida em O Capital. Aqui, para não perder o foco estrito na ontologia e na metodologia da teoria econômica, que não é um saber crítico como tal, mas um saber meramente explanatório, ela será colocada amplamente entre parênteses. Justamente por isso, aliás, o saber crítico não está no âmbito de uma teoria econômica, de uma microeconomia.

5 Esta seção do artigo baseia-se em parte numa apresentação das ontologias e metodologias das ciências sociais feita por Bunge no livro Epistemologia. Aí, esse autor distingue três concepções básicas de sociedade, as quais são denominadas de individualismo, globalismo e sistemismo (Bunge, 1980, p. 167-182). 
ela se esmera para obedecer, com a maior exatidão possível, aos princípios da lógica clássica: ou seja, da identidade, da nãocontradição e do terceiro excluído. Essa pretensão lógica carrega consigo, entretanto, um pressuposto ontológico muito significativo: os elementos individuais que entram na arquitetura analítica têm necessariamente de ser entidades fechadas em si mesmas e exteriores umas em relação às outras. Disso decorre que as totalidades sociais vêm a ser sempre concebidas como agregados ou conjuntos de indivíduos considerados, eles mesmos, como átomos sociais. Em conseqüência do fato de que, assim, essas totalidades não têm qualquer estatuto ontológico independente das partes que as compõem, qualquer propriedade social apenas pode aparecer como algo estritamente resultante das propriedades desses indivíduos.

Ademais, nessa perspectiva, as totalidades sociais como tais não podem influir ou atuar sobre os indivíduos: estes figuram na análise como fontes de ação e de decisão independentes, mesmo se são firmas, sindicatos ou países. A microeconomia reducionista suspeita da idéia segundo a qual as entidades sociais têm uma realidade própria e que elas apresentam propriedades autônomas em relação às propriedades de seus membros. Assim, por exemplo, ela encara as instituições apenas como idealidades sociais postas coletivamente pela subjetividade humana, ou seja, como "coisas" que apenas existem na mente dos indivíduos. Além disso, ela suspeita também do comportamento individual orientado em função de instituições supra-individuais. Os indivíduos que compõem a sociedade, por assim dizer, permanecem isolados das determinações vindas da sociedade. Em conseqüência dessa autonomia, as próprias interações sociais apareçam sempre como meras relações causais entre os componentes do todo social. Eis que essa microeconomia é capaz apenas de considerar as chamadas externalidades, ou seja, os efeitos das decisões de uns que mudam meramente as condições de escolha de outros.

A microeconomia reducionista orienta-se por princípios metodológicos consistentes em tese com esses supostos ontológicos, os quais aparecem enfeixados na noção de individualismo metodológico. Segundo essa noção, a explicação de qualquer regularidade econômica ou social deve ser invariavelmente remetida às propriedades dos membros componentes da totalidade social em que ela aparece. $\mathrm{Na}$ perspectiva da cientificidade atomista, a explicação dos fatos só pode ser 
legitimamente encontrada na conduta individual e na decisão privada de agentes autocentrados.

A confluência desses supostos ontológicos e metodológicos pode ser esquematicamente resumida na Figura $1 .^{6}$ Esta apresenta um problema genérico de explanação econômica em dois níveis: micro e macroeconômico; e o faz por meio de dois movimentos: um deles, analítico, que vai do nível macrossocial para o nível microssocial e o outro, sintético, que segue o caminho contrário. O primeiro movimento decompõe a regularidade macroeconômica; já o segundo agrega as ações dos indivíduos, resolvendo simultaneamente um problema de coordenação. Em conjunto, esses caminhos formam -e isto é crucial - um percurso de sentido unidirecional.

Já a microeconomia sistêmica é sustentada por uma ontologia social que admite a existência de todos formados por indivíduos interligados por estruturas $^{7}$ sociais objetivas - sem supor, entretanto, que esse "todo" seja realidade transcendente aos seus membros ou super-realidade no interior da qual os indivíduos seriam meros epifenômenos.

\section{Figura 1_ Microeconomia Reducionista}

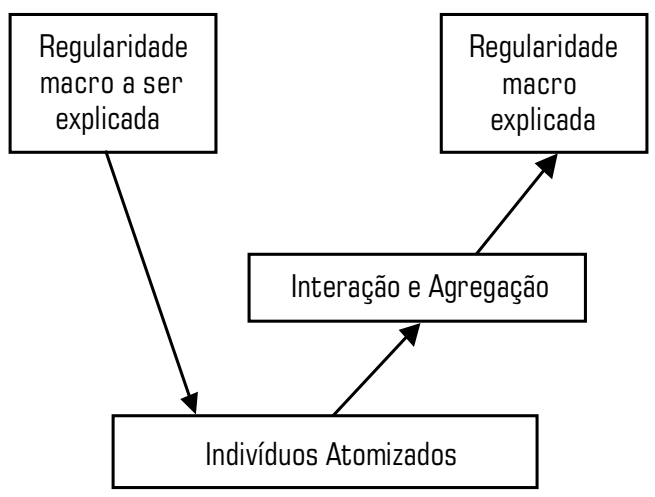

6 A figura aqui apresentada baseia-se em figura similar encontrada em Coleman (1994, p. 1-23) e em Janssen (1993).

7 Grosso modo, o termo "estrutura" designa o modo de organização próprio dos elementos de um sistema (Bertalanffy, 1969, p. 54). 
8 Sobre isso, diz Auyang,

"Composição não é mera agregação; os constituintes de uma composição interagem e a interação gera estruturas. Também não é meramente interação; pois, adicionalmente, tais composições são totalidades que possuem as suas próprias propriedades" (Auyang, 1998, p. 1).
Os todos e as partes não são opostos de modo absoluto nessa microeconomia. Em conseqüência, nela se assume que essas composições sociais estruturadas ${ }^{8}$ têm propriedades próprias, as quais emergem das ações e interações sociais constituintes. Tais atributos pertencem aos compostos, sem pertencer, entretanto, aos componentes. Ademais, essas propriedades sistêmicas encontram-se enraizadas nos comportamentos individuais, mas eles, em si mesmos, apenas respondem por elas por meio da mediação de processos que têm certa autonomia. Eis que as interações são agora concebidas como expressões de relações sociais, as quais não são meras conexões externas, mas relações que constituem em parte os próprios agentes sociais como tais, produzindo, ao mesmo tempo, a própria realidade sistêmica com características intrínsecas e particulares.

Os todos sociais, ademais, caracterizam-se também por serem complexos, pois são formados por elementos heterogêneos que se interligam heterogeneamente, com elevadíssima multiplicidade. A concepção de economia como sistema implica supor, por isso, que os funcionamentos econômicos não são transparentes para os agentes, ou seja, que estes últimos são parcialmente cegos aos eventos macrossociais. As propriedades emergentes no nível macroeconômico atuam de certo modo sobre os indivíduos, uma vez que suas ações e decisões têm conseqüências não intencionais, as quais retroagem sobre eles próprios. $\mathrm{Na}$ esfera da microeconomia sistêmica, portanto, é necessário pensar as instituições como existências sociais objetivas, supra-individuais, que determinam em parte o comportamento dos indivíduos, cujas ações, em última análise, inconscientemente ou subconscientemente, são responsáveis por elas. A microeconomia institucionalista, como também poderia ser chamada, admite, por exemplo, que o comportamento dos indivíduos pode estar determinado em parte pelas funções que exercem na organização social.

No âmbito da crítica da economia política, o sistema econômico existente foi encarado como o sistema da relação de capital. Foi tratado, então, como um sistema que se caracteriza por estar governado por um princípio de desenvolvimento infinito, por possuir um funcionamento global que escapa do controle dos agentes, os quais por isso mesmo são tidos como suportes ou funções das próprias relações de produção. Em vez de ser um sistema que se reproduz segundo metas postas pela ação política consciente dos homens, mostra-se então como um sistema que se reproduz segundo au- 
tomatismos, que depende de formas fetichistas e que sabota o caráter reflexivo da ação humana individual e coletiva.

A microeconomia sistêmica não é compatível com o individualismo metodológico, ainda que haja autores dispostos a sustentar que este último pode ser enxergado de um modo alargado que abre espaço para a determinação institucional das ações e decisões individuais (Latsis, 1976). Como isso implica, de certo modo, acolher uma contradição - os indivíduos determinam as instituições, $\mathrm{e}$ as instituições determinam os indivíduos -, há também autores que excluem essa possibilidade, assumindo que as preferências dos agentes da microeconomia neoclássica são determinadas exclusiva mente pelos desejos e pela apreensão de fatos ditos naturais (Boland, 1982).

$\mathrm{Na}$ verdade, a metodologia da microeconomia sistêmica requer muito mais do que um individualismo institucionalista. Exige que a explanação das propriedades macrossociais nesse campo do conhecimento seja remetida sempre à síntese entre propriedades individuais e relacionais, já que é exatamente isso o que está implicado no conceito de sistema. Assim, o próprio comportamento individual é explicado em função de características psicológicas, posicionais, interativas, etc. do "indivíduo em sociedade", visto que, nessa perspectiva, o indivíduo sem a sociedade é uma má abstração. Nessa perspectiva, pois, o próprio conceito de indivíduo já envolve o conceito de sistema, ou ainda, melhor dizendo, os conceitos de indivíduo e sistema se requerem mutuamente.

Tal como anteriormente, a combinação das características ontológicas e metodológicas da microeconomia sistêmica pode ser apresentada esquematicamente. A explanação, agora, segue um caminho mais complicado. Inicia-se com um movimento de análise que vai não só aos indivíduos, mas busca apreender também como eles se encontram organizados. Admite, assim, explicitamente, que a própria estrutura determina em parte o comportamento dos indivíduos ditos socializados. A interação dos indivíduos condicionada pela estrutura define o modo de composição do sistema, que, por sua vez, modifica em processo o comportamento dos indivíduos. Por isso, a explanação aqui é necessariamente dinâmica. O movimento sintético que explica a propriedade macroeconômica parte dos indivíduos, mas o faz também pela composição do sistema. $O$ fenômeno explicado é dito emergente porque ele não decorre, por redução, apenas das propriedades intrínsecas dos indivíduos, mas se deriva em parte delas, mas também em parte das relações que eles travam sob os constrangimentos da estrutura. 
Figura 2_Microeconomia Reducionista

9 Tratando não das teorias científicas enquanto tais, mas da teoria da própria ciência, o filósofo popperiano, Hans Albert, expressa tudo isso de um modo inequívoco. $\mathrm{Na}$ ciência, diz ele, "não se aspira à justificação do existente através do recurso a fundamentos seguros, e sim à sua refutação por meio do teste de contradições. Assim pode-se dizer, em verdade, que aqui dialética e evolução se encontram relacionadas num sentido bem determinado, enquanto que, por um lado, o pensamento axiomático, ligado ao monismo teórico, tende muito facilmente, por trás da aspiração a um fundamento seguro, a dar valor à persistência, à insistência no que até então vigora" (Albert, 1976, p. 61).

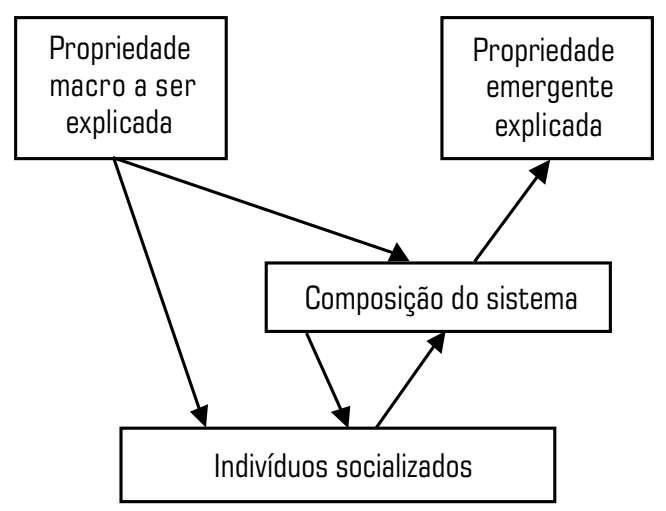

Há um problema lógico inerente ao discurso teórico nessa espécie de microeconomia que é preciso mencionar. Ela requer, por um lado, que se tenha uma visão dos agentes econômicos como seres mutáveis, adaptativos; exige, por outro, que se compreendam os fenômenos econômicos como processos de mudança, evolucionários. Eis que isso implica supor que os próprios objetos sob exame científico não permaneçam idênticos a si mesmos, mas que, ao contrário, se transformem constantemente sob a lente da teoria: os indivíduos aprendem, adquirem comportamentos, mudam as próprias expectativas; os sistemas passam por mutações, apresentam propriedades emergentes e de auto-organização. Em conseqüência, não se constituem como objetos que se submetem facilmente à lógica da identidade. Ao não permanecerem sob o foco do estudo, eles impedem que se possa apreendê-los estritamente por meio do método axiomático e dedutivo.

Essa dificuldade poderia sugerir que se chamasse o método científico inerente à teoria sistêmica de dialética ${ }^{9}$ mas não aqui porque se assume as contradições, mas porque se as reconhece 
nos movimentos processuais, procurando evitá-las. ${ }^{10}$ Assim compreendido, esse método não coage o teórico a tomar as contradições como objetivas - ora, era exatamente isso o que fizeram Hegel e Marx $^{11}$-, mas o obriga a um permanente esforço para fazer distinções analíticas: por um lado, o objeto é isso; por outro, o mesmo objeto é aquilo. Pois, o desdobramento analítico do objeto é uma operação necessária ao discurso científico que visa apreendê-lo quando o próprio objeto está em processo de mudança e de transformação ao longo do tempo.

Em resumo: na esfera da microeconomia reducionista, pensa-se a esfera economia como um conjunto de indivíduos atômicos cujas propriedades globais são devidas aos próprios indivíduos; já na esfera da microeconomia sistêmica, concebe-se a economia como um sistema adaptativo complexo que tem propriedades emergentes e que é capaz de auto-organização. A título de exemplo ilustrativo, lembre-se de que os preços na teoria neoclássica estão já, desde o início, implícitos nas preferências individuais, ao passo que, na teoria clássica, eles são fenômenos emergentes no mercado. Enquanto, na teoria neoclássica, os preços são explicados como propriedade da consistência agregada dos planos individuais, na teoria clássica, eles surgem da ação adaptativa dos agentes, mas flutuam fora do equilíbrio em torno de um atrator sistêmico chamado de preço natural ou de preço de produção.

\section{3_ Microeconomia reducionista}

A microeconomia dominante se enxerga como teoria científica que adere firmemente ao paradigma do individualismo metodológico, segundo o qual as explicações dos fatos econômicos em geral devem ser construídas, em exclusivo, com base em suposições concernentes ao comportamento dos indivíduos. Em conseqüência, nela se trabalha com dois níveis de análise: o plano dos indivíduos, o qual compreende unidades de decisão, tais como consumidores, investidores, empresas, etc., e o plano dos agregados, em que se trata grosso modo das propriedades inerentes aos mercados ou mesmo das propriedades da economia como um todo.

As decisões individuais são descritas como comportamentos racionais, os quais buscam escolher o melhor curso de ação possível para obter um dado objetivo viável, com base no melhor uso da informação disponível. Supõe-se que os agentes possuem ordenações de preferências sobre todos os resultados eventu-
.

10 Popper, um campeão do anti-hegelianismo e do antimarxismo, poderia perfeitamente ter chegado a essa conclusão. Em “'O que é dialética?” (Popper, 1982), ele aceita a tríade "tese, antítese e síntese", mas refuta ingenuamente Hegel e Marx, pensando que eles assumem como existente a própria contradição que a lógica formal rejeita. Popper ignora que esses dois autores apreendem a contradição fazendo distinção entre posição e pressuposição no interior da própria contradição, de tal modo que o registro do "é" se distingue do registro do "não é", ainda que eles se pertençam um ao outro, formando uma unidade (Ver Fausto, 1983)

11 Nessa perspectiva, Duncan Foley sugere que "a dialética pode ser utilmente entendida como uma tentativa de encontrar uma linguagem precisa para discutir os fenômenos dos sistemas complexos e da autoorganização" (Foley, 2003, p. 8). Um ponto importante é perceber que as dialéticas hegeliana e marxiana vão além do evolucionismo, porque são capazes de apreender as reais possibilidades de mudanças estruturais. 
12 A própria instituição da propriedade privada, por exemplo, aparece na análise apenas por meio da restrição orçamentária. almente alcançáveis por suas ações, que permanecem constantes durante toda a análise. Os conjuntos das opções viáveis estão limitados pelas circunstâncias naturais e pelas instituições sociais. Estas últimas entram no quadro de análise, entretanto, apenas numa perspectiva minimalista. ${ }^{12}$ Às vezes se admite que as conseqüências das ações que podem ser tomadas pelos agentes lhes são perfeitamente conhecidas, mas essa circunstância limite pode ser enfraquecida pela suposição de que eles se defrontam com a existência de incerteza probabilística. Os agentes não apenas tomam a melhor decisão com base nas suas expectativas sobre as conseqüências de suas ações, mas se julga que eles empregam com consistência toda a informação disponível para formar uma expectativa a mais correta possível.

Em síntese, os agentes dessa microeconomia são calculistas competentes que se preocupam em geral com eles mesmos e se movem pela ambição de obter os maiores retornos possíveis. As interações entre eles têm sempre a forma jurídica de relações contratuais. $\mathrm{O}$ quadro institucional subjacente é, pois, o contrato entre livres proprietários privados, o qual caracteriza apenas, como é bem sabido, a aparência do sistema. Ademais, para fazer abstração completa de todos os outros elementos inerentes às interações humanas em geral, como a ignorância, a coerção, a assimetria de poder, etc. esses contratos são pensados como completos e decorrentes da expressa vontade soberana dos contratantes. Dito de outro modo, essa teoria supõe que os contratos entre os agentes incluam todas as circunstâncias possíveis que cercam as transações econômicas. Tudo isso se configura, evidentemente, como uma idealização de altíssima potência ideológica.

A resultante do conjunto das ações individuais é um fato social no plano agregado e que se manifesta como um estado de equilíbrio. Esse estado que figura como mero resultado é implicitamente visado por elas, com maior ou menor precisão. De qualquer modo, é aqui, na passagem do nível individual para o nível agregado, que aparece a obra do método reducionista, o qual se encontra, entretanto, desde o começo, no cerne dessa microeconomia, uma vez que as propriedades dos indivíduos antes referidas, e que pareceram primeiras em relação ao momento da agregação, foram na verdade talhadas na medida exata para a aplicação desse método. O caminho que vai do fenômeno agregado a ser explicado às propriedades relevantes dos indivíduos consiste numa decomposição. Por meio 
dela, os indivíduos são tomados como átomos plenamente constituídos e que interagem entre si, direta ou indiretamente, de modo estritamente externo, sem que cada um deles possa influir ou mudar as determinações de qualquer outro. $\mathrm{O}$ caminho que vai das propriedades atômicas dos indivíduos para o fenômeno explicado é o da mera agregação (que não é, necessariamente, uma operação trivial).

Um exemplo canônico de explanação de microeconomia reducionista é o jogo denominado genericamente de "dilema do prisioneiro". Tal jogo configura uma situação de interação social típica em que se enfrentam dois agentes egoístas, ambos substantivamente racionais, que têm duas opções estratégicas: cooperar ou se eximir de fazê-lo. Os retornos da interação estão associados a um bem coletivo que apenas pode ser produzido se ambos cooperarem. O jogo conquanto tal visa apresentar um contexto social em que há contradição entre os interesses individuais e os interesses coletivos. Para melhor caracterizar a situação como um encontro de agentes individualistas, su- pôs-se na construção do exemplo que os retornos esperados (pay-offs) são próprios dos indivíduos envolvidos. Assim, como se vê na figura abaixo, o jogador da linha obtém retornos subjetivos substancialmente superiores ao jogador da coluna.

Como se sabe, essa interação de apenas uma fase tem um equilíbrio de estratégia dominante, e ele é um resultado inferior do ponto de vista do bem-estar dos agentes, já que a opção de mútua cooperação produziria um resultado melhor para cada um deles. Como os jogadores maximizam o próprio retorno estritamente de um modo autocentrado, na situação desse jogo, eles não conseguem produzir o bem coletivo que os colocaria em melhor situação. Ainda que a racionalidade individual produza aqui um resultado irracional do ponto de vista coletivo, esse resultado não pode ser atribuído a uma suposta fraqueza do método de análise, já que esse jogo obedece rigorosamente às condições do método reducionista. Dito de outro modo, nesse modelo o equilíbrio é um resultado estrito da agregação de decisões individuais. ${ }^{13}$

\begin{tabular}{|c|c|c|}
\hline & Cooperação & Defecção \\
\hline Cooperação & $30 ; 3$ & $0 ; 4$ \\
\hline Defecção & $40 ; 0$ & $* 10 ; 1 *$ \\
\hline
\end{tabular}

13 O dilema do prisioneiro mostra, por outro lado, que a apologia das interações estratégicas, e dos contratos nelas baseados, também tem o seu limite. 
$14 \mathrm{O}$ autor escreve "aggregate outcomes", mas é evidente que ele quer se referir a resultados que aqui são chamados de "sistêmicos".

\section{Microeconomia sistêmica}

Um tratado recente que apresenta de modo integrado e em extenso as concepções da microeconomia sistêmica, aí qualificada como evolucionária e institucional, busca de modo bem significativo

apresentar a teoria que versa sobre como os comportamentos individuais e as instituições econômicas interagem para produzir resultados agregados ${ }^{14}$ e sobre como os individuos e as instituiçoes mudam no tempo (Bowles, 2004, p. 8).

O que já mostra de uma maneira sintética que essa microeconomia se caracteriza por ser não-reducionista, ou seja, por não permitir que se concebam as totalidades em geral como meras somas de indivíduos. Ao contrário, indica que se tem de pensar essas composições como modos estruturados de organização social - isto é, como sistemas -, os quais têm uma dinâmica própria bem complexa e que, por isso mesmo, não podem ser tomados como apreensíveis pela razão científica de modo pleno. Rigorosamente, a ciência os entende conceitualmente, apenas em princípio, sem pretender representá-los ou representar fielmente o seu comportamento.

Nesse modo alternativo de pensamento microeconômico, as ações são ainda concebidas como intencionais, mas elas têm sempre conseqüências não intencionais. Os agentes têm metas e procuram alcançá-las, mas não são senhores autocentrados no contexto da interação. Ao contrário, são pensados como seres limitados tanto em sua capacidade cognitiva quanto em sua competência para agir racionalmente. Como tais, eles podem ter preferências que abarcam tanto interesses próprios quanto interesses sociais, nem sempre distinguíveis com a clareza da análise reducionista que opera só por meio da dedução. Em função do contexto em que se encontram, eles podem agir - empregando uma terminologia padrão - de modo egoísta ou altruísta. Em geral, em microeconomia sistêmica prefere-se pensar a população de agentes como heterogênea. Assim, julga-se aí que se deve conceber situações em que os agentes diferem entre si, por exemplo, quanto ao grau com que dão suporte aos interesses e bens coletivos.

Segundo a microeconomia sistêmica, os indivíduos, as organizações e os mercados co-evolvem. Os sistemas de interações não são estáticos, mas evolucionários. $\mathrm{E}$ isso tem algumas implicações interessantes: nessa perspectiva, por exemplo, tornam-se muito importantes os retornos crescentes de escala que afetam um amplo conjunto de processos, entre os quais os tecnológicos. Tais retornos aparecem quando certas ações ou atividades apresentam resultados que aumentam mais do que proporcionalmente quando, por exemplo, cresce o núme- 
ro de pessoas por elas responsáveis. Os processos de realimentação negativa ou constante dão origem a comportamentos sistêmicos que tendem a estados de equilíbrio estatístico-estacionários. Já os processos de realimentação positiva estão ligados tanto às transformações e ao aparecimento de fases, assim como do novo, quanto à dependência de trajetória e ao auto-encerramento (lock-in).

A microeconomia sistêmica também se vale de modelos, mas as técnicas matemáticas empregadas diferem em certa medida daquelas utilizadas pela microeconomia reducionista. Ambas utilizam os instrumentos do Cálculo Diferencial e Integral, mas mesmo aqui subsistem diferenças: se a última emprega especialmente as técnicas de otimização estática e dinâmica, a primeira concentra-se no uso das equações diferenciais e a diferenças finitas. Se a última tem preferência toda especial pelo método axiomático dedutivo e pela análise topológica, a primeira aprecia bastante a matemática experimental e os sistemas dinâmicos não lineares, os quais hoje empregam intensamente, ainda que não em exclusivo, as simulações computacionais para apreender os ciclos, os comportamentos caóticos, as bifurcações e os atratores estranhos. Em especial, a microeconomia sistêmica, na formu- lação de modelos, propõe-se atualmente a empregar certas técnicas matemáticas desenvolvidas depois do advento da "prova de Gödel" e do conseqüente colapso do programa formalista de Hilbert: sistemas classificadores, algoritmos genéticos, autômatos celulares, teorias do campo aleatório, etc. ${ }^{15}$

No campo das analogias com as ciências naturais, também se observam diferenças importantes. Se a microeconomia neoclássica, por exemplo, utiliza principalmente do formalismo da termodinâmica clássica, ${ }^{16}$ subsiste atualmente uma série de tentativa de empregar os formalismos da mecânica estatística moderna. As teorias dos campos aleatórios e das transições de fase estão sendo utilizadas com o objetivo de entender melhor alguns aspectos da realidade econômica ligados às interações sistêmicas de múltiplos agentes. ${ }^{17}$ Se a microeconomia consagrada continua se desenvolvendo por meio do emprego da teoria dos jogos tradicional, que trata da tomada de decisões simultâneas ou sucessivas num contexto estático, a nova microeconomia faz uso da teoria dos jogos evolucionários, a qual se desenvolveu primeiro no campo da Biologia Matemática. Ademais, a Economia está hoje procurando acompanhar $\ldots \ldots \ldots$

15 As técnicas matemáticas e os conceitos empregados na teoria dos sistemas complexos adaptativos estão apresentados, de modo didático, em Casti (1992).

16 Mirowski mostrou como um desejo de aproximar a Economia Política da Física Matemática motivou o surgimento da teoria neoclássica, indicando também como essa meta foi realizada por meio da incorporação no seio da primeira do formalismo termodinâmico desenvolvido nesta segunda ciência (Mirowski, 1984). Foley, por outro lado, apontou inequivocamente como a noção de equilíbrio dos modelos de equilíbrio geral é um caso especial do equilíbrio estatístico, quando a entropia informacional do sistema é tornada zero (Foley, 1994).

17 Freitas empregou essa técnica no Brasil com resultados interessantes (Freitas, 2003). 
as ciências naturais que tomaram a iniciativa de estudar formalmente os processos de auto-organização, os quais combinam características estocásticas e deterministas, fazendo uso da chamada "teoria dos processos ergódigos".

Pode-se ilustrar o modo de explanação da microeconomia sistêmica comparando-o com o modo da microeconomia reducionista. Para isso, pode-se ampliar o dilema do prisioneiro antes apresentado por meio da consideração de uma estrutura social mais rica. Admita-se, por um momento, que os agentes são ainda, de início, calculistas competentes, mas que eles dispõem, agora, de uma estratégica adicional que expressa um princípio normativo de reciprocidade. Essa estratégia, usualmente chamada de tit-for-tat, consiste na seguinte regra de comportamento: se o outro coopera, o agente também coopera; caso, entretanto, o outro opte pela defecção, o agente em consideração acompanha essa opção para minimizar a sua perda. É patente que essa norma só pode vir a existir se a relação social entre os jogadores for constitutiva das suas preferências. Em conseqüência, na hipótese de que eles venham a adotá-la, deixam de se preocupar exclusivamente com eles mesmos. Ao adi- cioná-la às opções do jogo, o homo economicus já está sendo transformado em homo reciprocans (Gintis e Bowles, 1998).

A matriz de retornos, em que esses estão agora expressos em valores supostamente objetivos (por exemplo, em dinheiro), encontra-se abaixo. Um estudo desse jogo sob a perspectiva da estratégia de melhor resposta de cada um dos jogadores, em face de cada uma das opções possíveis do outro, mostra que há dois equilíbrios de Nash. Ora, essas soluções são características da metodologia reducionista. Elas permitem pensar, se os agentes estiverem posicionados num desses equilíbrios, que eles não terão estímulos para se desviarem para uma outra estratégia; mas essa metodologia nada permite dizer sobre como eles podem alcançá-lo. Ao se concentrar na situação de equilíbrio como um resultado que advém de um processo de otimização, esse modo de análise se impede de teorizar sobre o processo por meio do qual a situação de equilíbrio pode vir a ser obtida. Como a estratégia de reciprocação é normativa, e a opção estratégica que a viabiliza é meramente instrumental, haverá uma inconsistência nessa solução do jogo de interação se ela for proposta. 


\begin{tabular}{|c|c|c|c|}
\hline & Cooperação & Defecção & Reciprocação \\
\hline Cooperação & $3 ; 3$ & $0 ; 4^{*}$ & $* 3 ; 3$ \\
\hline Defecção & $* 4 ; 0$ & $* 1 ; 1 *$ & $1 ; 1 *$ \\
\hline Reciprocação & $3 ; 3^{*}$ & $* 1 ; 1$ & $* 3 ; 3 *$ \\
\hline
\end{tabular}

A solução para esse problema teórico vem a se repensar o problema no contexto de um jogo evolucionário, cuja preocupação central é a dinâmica fora do equilíbrio. Nesse jogo populacional, as estratégias são normas de comportamentos que os agentes podem eventualmente seguir. Esses, agora dotados de racionalidade limitada, escolhem individual e conscientemente as estratégias disponíveis, mas, conquanto um todo populacional, convergem inconscientemente para uma solução, ou seja, para determinada estratégia ou para uma combinação delas, por meio de um processo de aprendizagem e de formação de si mesmos.

Para pensar a solução de um modo ilustrativo, suponha-se que há um estado originário em que todos os membros da população, quando se enfrentam em encontros bilaterais, optam constantemente pela defecção. Eles vivem, por assim dizer, num estado de natureza, levados que foram por uma mão invisível maléfica. Suponha-se que alguns deles, em certo momento, descobrem a opção de reciprocação e passem a experimentála eventualmente. Inicialmente, essa ação ainda não se afigura para eles como uma norma social válida, mas apenas como uma oportunidade de testar uma alternativa. À medida que fazem experimentos, verificam que o seu próprio retorno médio aumenta, ou seja, descobrem aos poucos que o comportamento mais cooperativo é mais vantajoso. Ao fazê-lo, passam a considerar aqueles com que cooperam como parceiros. Suponha-se, também, que os membros da população menos bem-sucedidos sejam capazes de imitar o comportamento dos membros melhor sucedidos.

Assim, o comportamento de reciprocação, aos poucos, passa a ser adotado generalizadamente pela população, de tal modo que ela passa a viver, agora, no estado de sociedade. Do ponto de vista do jogo evolucionário, esse processo equivale ao deslocamento de um equilíbrio para outro. Conceitualmente, o comportamento estratégico assim se transforma num comportamento normativo, e este é um resultado que emerge - é incutido na 
18 A apresentação formal e completa desse jogo e de sua solução requer muitas páginas, e não apenas um parágrafo. Uma formalização com base em dinâmica de replicação pode ser encontrada num estudo do autor (Prado, 1999). Ver também Axelrod (1984).

19 Como se sabe, os "pés de barro" da teoria neoclássica contemporânea são os teoremas de Sonnenschein, Debreu e Mantel (Soromenho, 2000). mente dos jogadores - sem que eles o tenham buscado conscientemente. Trata-se de um resultado não intencional de ações intencionais cegas, ou seja, um produto social legítimo da mão invisível que, nesse caso, atua beneficamente. ${ }^{18}$

\section{5_Conclusões}

Diante da existência dessas duas alternativas, quais seriam as perspectivas de desenvolvimento da microeconomia em geral? A microeconomia sistêmica, que pensa o sistema econômico fora do equilíbrio, poderá superar a microeconomia reducionista, que o pensa essencialmente no equilíbrio? Eis aqui perguntas a que a própria visão de mundo sistêmica e evolucionária considera difícil responder. Pois, para ela, o futuro é incerto e pode reservar muitos caminhos alternativos para a teoria econômica estabelecida. Apesar da alternativa hoje consagrada ser bem inferior à outra eventualmente emergente, até porque, de um ponto de vista teórico, pode ser encarada como esfera de seus casos particulares (para a microeconomia reducionista, grosso modo, os processos econômicos no mundo real convergem sempre para atratores de ponto fixo), a primeira tem a força de uma concepção dominante. De qualquer modo, a micro- economia sistêmica pode ser desenvolvida para enfrentar todos os problemas relevantes no campo da Economia Política, desde a formação de preços até as crises financeiras (Arthur, 2005).

Apresentar a Economia capitalista por sua aparência mercantil e como resultante estável de decisões particulares que se originam, por sua vez, de indivíduos movidos pelo retorno privado e dotados de racionalidade clarividente e eficiente - ou seja, como agregados em estados de equilíbrio -, parece bem confortável diante das turbulências e dos dilaceramentos da realidade econômica em permanente transformação. Por outro lado, entretanto, a ciência tem dinâmica própria, que pode surpreender os seguidores do ramerrão teórico e pouco reflexivo contido nos livros-textos. Esses se julgam ainda instalados em fortalezas, mas os teóricos de fronteira da própria teoria neoclássica sabem bem hoje que o gigante está enfraquecido e que ele tem pés de barro. ${ }^{19}$ É de se acreditar, porém, que a força dos argumentos possa ter ainda papel importante na trajetória da teoria econômica, ainda que a cultura dominante possa ter entrado na fase pós-moderna. Saber, entretanto, quão decisivo poderão ser os argumentos racionais em face dos preconceitos ideológicos para definir o 
futuro da microeconomia é até certo ponto uma grande incógnita.

Há, entretanto, diferenciais que podem favorecer a microeconomia sistêmica. Ela está em consonância com certos desenvolvimentos atuais das ciências naturais, os quais estão voltados à apreensão e à compreensão de certos processos de que estão na origem das formas existentes de auto-organização, seja no mundo inanimado, seja na esfera da vida, seja ainda na esfera da inteligência. ${ }^{20} \mathrm{O}$ estudo da emergência de formas mais complexas de organização da matéria, valendo-se de formas menos complexas, é um objeto privilegiado de estudo no encontro, por exemplo, da Química Orgânica e da Biologia (Kauffman, 1995). À medida que a microeconomia sistêmica pode dispor hoje de formalismos matemáticos avançados (Boccara, 2004), em especial aqueles da Matemática recursiva (Wolfram, 2002; Velupillai, 2000), ela pode sair da defensiva para fazer vir à luz uma visão mais profunda da realidade econômica em processo. Eis que aqui também, por um lado, podem existir retornos crescentes em escala. Por outro lado, como a sociedade humana em todas as esferas possui freios conservadores, é possível que esse potencial de desenvolvimento possa ser contido ainda por um largo tempo.

\footnotetext{
20 U. . . . . . . . . Uma introdução didática popular e muito difundida às chamadas "ciências da complexidade" vem a ser o livro de Coveney e Highfield (1995). Um tratado sobre o desenvolvimento da Biologia evolucionária é a obra magna de Stephen J. Gould (2002).
} 


\section{Referências bibliográficas}

\author{
ALBERT, H. Tratado da razão \\ crítica. Rio de Janeiro: Tempo \\ Brasileiro, 1976.
}

ARTHUR, W. B.

Out-of-equilibrium economics and agent-based modeling. In: Handbook of computational economics. v. 2. Ed. K. Judd e L.

Tesfatsion: Elsevier/

North-Holland, 2005.

AXELROD, R. The evolution of cooperation. Basic Books, 1984.

AUYANG, S. Y. Foundations of complex-system theories in Economics, evolutionary Biology, and statistical Physics. Cambridge University Press, 1998.

BATEMAN, B. W. Human logic and Keynes's economics:

a comment. Eastern Economic Journal, v. 15, n. 1, Jan./Mar. 1989.

BERTALANFFY, L. von. General SystemTheory - Foundations, development, applications. New York: George Braziller, 1969.

BOCCARA, N. Modeling complex systems. Springer, 2004.

BOLAND, L. The foundation. of Economic Method. Alen and Unwin, 1982.
BOWLES, S. Microeconomics behavior, institutions, and evolution. Princeton University Press, 2004.

BUNGE, M. Epistemologia - Curso de Atualização. São Paulo: T. A

Queiroz e Editora da

Universidade de São Paulo, 1980.

CASTI, J. L. Reality Rules I

(The Fundamentals) e Reality Rules II

(The Frontier). New York: John

Willey \$ Sons, 1992

COLEMAN, J. S. Foundations of Social Theory. Harvard University Press, 1994.

COVENEY, P.; HIGHFIELD,

R. Frontiers of complexity

- The search of order in a chaotic world. New York: Fawcett

Columbine, 1995.

FAUSTO, R. Dialética marxista, humanismo e anti-humanismo. In: Marx - Lógica \& Política (v. I). São Paulo: Brasiliense, 1983.

FOLEY, D. K. A Statistical equilibrium Theory of Markets. Journal of Economic Theory, v. 62 n. 2, p. 321-345, 1994
FOLEY, D. K. Unboly trinity Labor, capital, and land in the new economy. Routledge, 2003.

FREITAS, G. G. Economia e sistemas complexos: interações sociais, dinâmicas emergentes e uma análise da difusão da internet na cidade de São Paulo. 2003. Dissertação (Mestrado em Economia) - Universidade de São Paulo, São Paulo, 2003.

GINTIS, H.; BOWLES, S.

Is equality passé? Homo reciprocans and the future of egalitarian politics. In: sítio dos autores, 1998.

GOULD, S. J. The structure of Evolutionary Theory. Harvard University Press, 2002.

JANSSEN, M. C. W.

Microeconomics - A critical inquiry. Routledge, 1993

KAUFFMAN, S. At bome in the universe - The search for the laws of self-organization and complexity. Oxford University Press, 1995.
LATSIS, S. J. A research programme in economics. In: Method and appraisal in Economics. Ed. Spiro J. Latsis. Cambridge University Press, 1976. MIROWSKI, P. Physics and 'marginalist revolution'. Cambridge Journal of Economics, v. 8, p. 361-379, 1984.

O'DONNELL, R. M. Keynes: Philosophy, Economics and Politics - The Philosophical Foundations of Keynes's Thought and their influence on his Economics and Politics. Macmillan, 1989.

PRADO, E. F. S. Elster e a mão-invisível. Lua Nova, n. 28/29, p. 297-312, 1993.

PRADO, E. F. S. Dilema do prisioneiro e dinâmicas evolucionárias. Estudos Econômicos, v. 29 , n. 2 , p. 249-266, abr./jun. 1999.

PRADO, E. F. S. Uma formalização da mão invisível. Estudos Econômicos, v. 36, n. 1, jan./mar. 2006. 
POPPER, K. R. Que é dialética?

Conjecturas e refutaçōes. Brasília:

Universidade de Brasília, 1982.

SCHELLING, T. C. Micromotives and macrobehavior. New York: W. W. Norton, 1978.

SIMON, H. A. From substantive to procedural rationality. In: Method and appraisal in Economics. Ed. Spiro J. Latsis. Cambridge University Press, 1976.

SOROMENHO, J. E. C.

Microfundamentos e

sociabilidade. Economia (Anpec), n. 2 , jan./jun. 2000.

VELUPILLAI, K. Computable economics. Oxford University Press, 2000.

VERCELLI, A. Racionalidade, aprendizagem e complexidade. Econômica, v. 7, n. 2, dez. 2005.

WOLFRAM, S. A new kind of science. Champaign (EUA):

Wolfram Media, 2002.

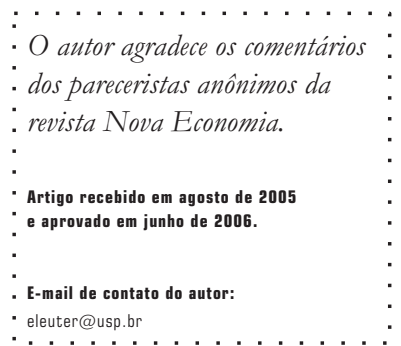

